\title{
High Altitude as an Environmental Economic Good: Estimating Its Economic Value Using Willingness to Incur Costs by Athletes
}

\author{
Silah Misoi", Andrew Kiptum \\ Department of Applied Environmental Social Science (Environmental Economics), University of Eldoret, Eldoret, Kenya \\ Email address: \\ kimi_12@hotmail.com (S. Misoi) \\ ${ }^{*}$ Corresponding author
}

To cite this article:

Silah Misoi, Andrew Kiptum. High Altitude as an Environmental Economic Good: Estimating Its Economic Value Using Willingness to Incur Costs by Athletes. International Journal of Economy, Energy and Environment. Vol. 5, No. 3, 2020, pp. 24-31. doi: $10.11648 /$ j.ijeee.20200503.11

Received: August 26, 2019; Accepted: October 21, 2019; Published: June 9, 2020

\begin{abstract}
High altitude training provides acclimatization to athletes by enhancing endurance; however, this environmental service has remained unaccounted and un-priced. Therefore, this study sought to estimate economic value of high altitude services to athletes using travel cost valuation approach. This study was carried out at Iten Township in Elgeyo Marakwet County, Kenya. Systematic simple random sampling technique was used in administering 223 structured questionnaires to respondents. Excel and Statistical Package for Social Sciences (SPSS version-20) were used for data analysis. Findings from the study showed that athletes incurred estimated cost of about $\$ 9.59$ per day to train at high altitude, while high altitude attributes such as experience, safety and altitude acclimatization were highly ranked as motivating factors by athletes to train in the study area. Results from statistical tests revealed that experience, age of athletes, safety and altitude effects were significantly difference in influencing athletes' willingness to incur extra cost for altitude acclimatization. Analysis from logit model showed that experience, age of athletes, safety and altitude effects had high probability to influence athletes to train at high altitude areas. However, stochastic variable in the model showed significant difference in influencing willingness to incur cost by athletes while training at high altitude. This error term explains unobserved variables in the model which were beyond the scope of this study. In conclusion athletes are willing to incur travelling and living costs to train at high altitude areas in order to gain incremental altitude training effects as affirmed by bootstrap hypothesis testing results. Significant of this study will inform policy and decision makers on critical information while they develop sustainable infrastructure, legislation and policies for sports industry.
\end{abstract}

Keywords: Altitude Training, Acclimatization, Willingness to Incur Cost, Travelling Cost and Living Costs

\section{Introduction}

High altitude provides services that are vital in sports training. Altitude services to sports training has remain unpriced and unaccounted [1]. This is because altitude services exhibit non-excludability, non-rivalry and non-market. Economists view market failures to occur when environmental elements remain non-priced and its services for economic development are supplied to the economic units for free [1-3].

Non-priced services often complicate maximization of resources to the adjacent-community and beyond during planning and utilization processes. When there is unaccounted economic value for high altitude services to sports training, policies that could stimulate the development of sports infrastructure that brings positive externalities gets low weight consideration [4]. In this study, benefits gained by athletes training at high altitude areas raises research gap in accounting altitude services. Incremental benefits gained by training at high altitude makes altitude services to be viewed as a gift of nature, making altitude zones and areas which is an invisible and unnoticed resources to be ranked lowly by policy makers [5].

Increasing terrestrial altitude has physiological effects to 
athletes who train at high altitude; that's increasing altitude causes a drop in barometric pressure of oxygen resulting to hypobaric hypoxic effects [6]. According to [7] hypoxic condition in high altitude areas is triggered by carotid body receptors to improve ventilation of an athlete and subsequent endurance performance in the long run. That's high altitude induces acclimatisation effects which influences sports performance. This induced body protection system from increasingly altitude exposure is known as acclimatisation [8]. As such, high altitudes service to athletes training has remained unaccounted, yet, it contributes immensely in the growth of sports industry.

Study [9] found altitude to have profound effects on the exercise and sports performance, thus, a fully rational athlete should seeks with cost to train to maximise altitude utility. Research [10,11] revealed altitude acclimatisation tend to improve endurance of an athlete and thus performance, though the magnitude of this improvement depends on the level of elevation and the duration of stay for acclimatization. For an athlete to gain maximum utility on altitude services and to gain high performance, specific altitude range (i.e. moderate altitude) and the number of days spend (long stay).

Since variances in acclimatisation levels are based on altitude zones and areas, $[8,11]$ categorised altitudes based on its acclimatisation effects to athletes. These training models are live high, train high (LHTH); live low, train high (LLTH) and live high, train low (LHTL). Therefore, altitudes levels are specific in acclimatization [6], thus athletes preference in choosing training zone and area is based on their sporting endurance demands.

Table 1. Categories of altitude.

\begin{tabular}{lll}
\hline Category & Altitude $(\mathbf{m})$ & Characteristic \\
\hline Low Altitude & $\leq 2000$ & High oxygen level \\
Mid altitude & $\leq 2000-3000 \geq$ & Moderate oxygen level \\
High altitude & $\leq 3000$ & Low oxygen level \\
\hline
\end{tabular}

Source: Adapted from Levine and Stray-Gundersen (2006).

Specific altitudes (Table 1) among athletes have emerged as a way to gain tactical advantage over the competitors at low altitude [11]. Based on that, athletes incur costs in search of altitude training zones and areas and convenient place to stay in order to attain high altitude acclimatisation effect. However, effects of altitude training on athletics performance seem to be at best minimum and temporary. Study by [6] found mid altitude areas (altitude between 2000 and 3000m above sea level) to be an optimal acclimatization zone for endurance type of sporting events such as mid, cross country and long distance, while high altitudes is prone to altitude illness which could be a detrimental. Again, [6] found three months at minimum for profound maximum acclimatization when exposed to high altitude zone and area.

Based on the characteristic of altitude level, its significance in aiding athletes to acclimatised for a better event performance, altitude services has remain unnoticed. Therefore, determining its economic value by valuing its services could give an understanding on the supply side effect to the economy. This would help policy makers in integrating altitude as a resource in development agenda. The focus in this study is to evaluate the consistency of economic value of altitude services to sports industry using random utility model with constructs of neoclassical economic theory.

Neoclassical economic theory states that utility is quasiconcave with respect to the output or equivalent, where that preference from various resources attributes if displayed using indifferent curve are convex to the origin [12]. Preference of altitude for sport training implies that athletes are willing to make substitution among available altitude levels subject to other underlying variables. On the other hand Random Utility Model (RUM) puts utility into deterministic $(\mathrm{x})$ and stochastic $(\varepsilon)$. In context to this study, altitude utility can be expressed in a functional form as;

$$
U_{i j}=f\left(x_{i j}, \varepsilon_{i j}\right)
$$

Where; $U_{i j}$ is the maximum utility athlete's $(i)$ gets from attribute $(\mathrm{j}), x_{i j}$ is the altitude attribute (experience, safety and etc) and $\varepsilon_{i j}$ represent other variables omitted in the model which influence its output.

RUM is derived from choice contingency modelling where individual trade-off bundles of goods based on its attributes [13]. In context to this study, an athlete (s) $(i)$ is expected to choose to train in a specific altitude zones and area (j) for acclimatization in preference of status quo $((\mathrm{k})$ - training at home area without incurring expenses such as travelling cost and living cost). This can be expressed in an equation function as;

$$
P_{i j}=\operatorname{prob}\left(U_{i j}>U_{i k}\right) ; \mathrm{j} \neq \mathrm{k} \text { and } \mathrm{j}>\mathrm{k}
$$

Where; $P_{i j}$ represent the probability of athlete making a choice to train at high altitude for acclimatization; $U_{i j}$ represent athletes' preference to train at high altitude away from home for acclimatization and $U_{i k}$ represent athletes' preference for status quo (avoids incurring cost and thus chooses not to travel to high altitude).

Acclimatization cannot be the only variables that motivates athlete to train at altitude, perhaps, other variables could contribute in motivating athlete to train at specific altitude zone and area. Hence, probabilistic equation can be expressed in this study to explicate realism from influencing covariates in the regression analysis tests as follows;

$$
\begin{array}{r}
P_{i j}=\operatorname{prob}\left[\left(\left|U_{i j}\right| \beta_{1} \exp +\beta_{2} \text { altserv }+\cdots \beta_{n} X_{n}+\varepsilon_{i j}\right)>\right. \\
\left.\left(\left|U_{i k}\right| \beta_{1} \exp +\beta_{2} \text { altserv }+\cdots \beta_{n} X_{n}+\varepsilon_{i k}\right)\right]
\end{array}
$$

The probability of athletes to choose to incur cost and train at altitude zone of choice over an alternative could be conditioned by individual training needs such as experience, altitude services or cost, age, environmental conditions among others. The preposition implies that people are willing to make substitution among diverse training zones with varying levels of acclimatization, however, altitude services to athletes may invoke lexicographic ordering effect based on ethical concerns. However, athlete's constraint with 
lexicographic preference would never be indifferent between various combinations of high altitude training conditions and cost incurred to meet training conditions for events.

Therefore, measure of the economic value using incremental body adaptability by training at altitude zone for acclimatization is the amount of money an individual is willing to pay to attain acclimatization which leaves an athlete just as well off than before. This measure is referred to compensating surplus. This compensating surplus (CS) can be expressed as the difference between two expenditure functions of status quo and athletes choosing to train at altitude area:

$$
C S=f\left(p, q_{0}\left(a_{0}\right), \mathrm{u}_{0}\right)-f\left(p, q_{1}\left(a_{1}\right), \mathrm{u}_{1}\right)
$$

Where; CS is compensating surplus, $\mathrm{p}$ is a vector of market prices, $\mathrm{q}$ is a measure of altitude condition which in turn is a function of altitude area for athletic training and $u$ being altitude utility. The subscript 0 refers to the status quo while 1 refers to the changed condition where athlete trains at high altitude area.

Cost incurred to train at high altitude for acclimatization purposes can be considered as an economic value for altitude services. Thus, in this study hypothesis to be tested is whether willingness to pay (WTP) or incur cost for acclimatization training at altitude could incrementally improve running performance is statistically different than zero. The null hypothesis can be expressed as:

$$
H_{0}: W T P_{a}=0
$$

Where; (a) is a measure of economic value of altitude services. The null is tested against the alternative that $W T P_{a}>0$.

If preference to train in altitude area is consistent with consumer theory, then athletes will be willing to incur cost as an expressed willingness to pay for enhanced running performance. However, gains in altitude training are specific and temporal. This could suggests a second null hypothesis that athletes training at altitude could gain higher training performance as utility, but do not gain marginal utility from all altitude areas other than specific zones and areas. To this hypothesis, we can formulate the null hypothesis that incremental willingness to incur cost for incremental gains by training in altitude areas is equal to zero. This hypothesis can be expressed in an equation form as:

$$
H_{0}: \int_{q 0}^{q 1} \emptyset\left(p, q(a), \mathrm{u}_{0}\right) \partial q=0
$$

Where; marginal willingness to incur cost for improved training at altitude $\varnothing\left(p, q(a), \mathrm{u}_{0}\right)$, is a partial derivative of the athlete expenditure function:

$$
\varnothing\left(p, q(a), \mathrm{u}_{0}\right)=\frac{-\partial e\left(p, \mathrm{q}_{1}\left(\mathrm{a}_{1}\right), \mathrm{u}_{0}\right)}{\partial q}=\frac{\partial W T P}{\partial q}
$$

The partial derivative represents the slope of the individual athlete's indifference curve at the point of evaluation, and marginal willingness to incur cost is integrated over the incremental change $\mathrm{q}_{0}\left(\mathrm{a}_{0}\right) \rightarrow \mathrm{q}_{1}\left(\mathrm{a}_{1}\right)$. Under the circumstance that we fail to reject the second hypothesis, it would imply that indifferent curve is flat with respect to athletes accepting cost and train at high altitude for acclimatization and subsequent better running performance a violation of the neoclassical assumption regarding nonsatiation. Therefore, we could let the incremental training performance from athlete's specific altitude choice be represented by $b$, which makes the formulation of the hypothesis as:

$$
H_{0}: W T P_{a+b}=W T P_{a}
$$

If null hypothesis in equation 8 is rejected which prompt alternative hypothesis that marginal willingness to incur cost by the athlete, then consistency of measured WTP with economic theory which requires that second derivative of WTP with respect to specific altitude area chosen by athlete for acclimatization function be negative. The WTP curvature condition can be evaluated by comparing the average slope of two segments of the WTP functions with respect to the specific area chosen by athlete for training at altitude. In particular to that, then the null hypothesis will be formulated as follows:

$$
H_{0}=\frac{W T P_{a+b}-W T P_{a}}{b}<\frac{W T P_{a}}{a}
$$

The numerator in each expression in equation (6) represents incremental utility from altitude training in respect to marginal increase by athlete to incur cost, where it is implicitly assumed that WTP for incremental improved running performance is zero, and the denominator represents the change in altitude training areas.

\section{Material and Methods}

\subsection{Description of Study Area}

This study was carried out in the month of January to March in the year 2018 at the Iten Township. The township is renowned as home to world beaters runners christened "home of Champion". Iten Township is found in Elgeyo Marakwet County which are part of high altitude areas Kenya. The township was selected as a study area because it is a convergent zone where the budding and elite athletes from local and international come to train there.

The study area lies between latitudes $0^{\circ} 30^{\prime} \mathrm{N}$ and $0^{\circ} 53^{\prime} \mathrm{N}$ and longitudes $35^{\circ} 20^{\prime} \mathrm{E}$ and $35^{\circ} 35^{\prime} \mathrm{E}$. The altitude is between $1400 \mathrm{~m}$ above sea level on the northern part and $2400 \mathrm{~m}$ above sea level on the southern part. The eastern part exhibits low valley that lies at $1100 \mathrm{~m}$ above sea level. The lower eastern part is the western rift valley branch, which gives a wider choice between low and high altitude to athletes training in the study area. The mean annual rainfall is $1800 \mathrm{~mm}$ with a pattern showing bimodal type of rainfall with the long rains between March and June, and short rains from September to November, while the temperature varies between $14^{\circ} \mathrm{C}$ and $24^{\circ} \mathrm{C}$ with lower altitude experiencing a higher temperature [14]. Climatic characteristic coupled with infrastructure development such as roads often used for 
training makes the study area to be attractive for non-local athletes as a good altitude training area.

\subsection{Sampling Procedure, Data Collection and Analysis}

Athletes often train in groups, and thus they often meet at a convergent point before and after training. The characteristic exhibited by athletes where they train in groups, informed the design of data collection for this study. Assemblage by athletes in various groups for training depends on their program schedules. This diverse grouping by athletes necessitates identification and selection of groups as clusters for data collection. Athletes in these training groups comprise a mix of local and foreign, purely local and foreign based athletes. Routine of training are during morning and evening hours and with different groups having unique training schedules. This made different groups to be easily identified for data collection and to avoid double selection.

Therefore, athlete's assemblage point in the study area which has been popularly named 'start and finish point' by athletesand coaches was questionnaires administrating point. First, a group was identified using camp they stay or leader or coach of the group and thereafter, respondents from identified group were randomly and systematic selected for interview. Since athletes reside in different apartments or camps, they often come to the assemblage point at different times. Based on their arrival time, respondents were selected based on their position of arrival; that's the first to arrive was selected and subsequent selection was done by selecting the third athlete to arrive from the group. This made sample selection to be systematic and randomly selected to avoid selection biases. Sampling followed similar format for all groups throughout sampling period. If in case athlete joined a different group and by chance selected as respondents, then that athlete will be omitted and the immediate athlete to arrive is selected.

The sample size required for sampling was achieved by using the following formula [15]:

$$
\mathrm{n}=\frac{\mathrm{NC}^{2}}{\mathrm{C}^{2}+(\mathrm{N}-1) \mathrm{e}^{2}}
$$

Where; $n$ - size of sample, $N$ - size of population and $C-$ coefficient of variation at $(30 \%)$ confidence limit, while $e$ is the standard error at $2 \%$ level.

Population of athletes training at Iten Township is estimated to be nearly 3800 . From the formula in equation (10), the sample size was then 213 athletes as respondents. To cater for spoilt and incomplete questionnaires, additional of 10 questionnaires were administered to make 223as sample size.

That's;

$$
\begin{gathered}
\mathrm{n}=\frac{3,800(0.3)^{2}}{(0.3)^{2}+(3800-1) 0.02^{2}} \\
\mathrm{n}=\frac{342}{1.6096} \equiv 213 \\
\mathrm{n}=213+10
\end{gathered}
$$

$$
\mathrm{n}=223 \text {. }
$$

Information that was sought from the respondents were athlete speciality in terms of race, cost incurred (travel and subsistence) while training, altitude of athletes home if he/she is a foreigner, purpose of training and reason of choosing Iten township. All these information were conceptualized for regression analysis and later interpretation. Relationship of identified parameter in this study can be expressed in an Ordinary Least Squares (OLS) equation as:

$$
Y=a+b_{i} X_{i} \ldots b_{n} X_{n}+\varepsilon_{i}
$$

Where:

$Y$ - Represent dependent variable which is the cost incurred by training at attitude.

$X_{i}-$ Motivating needs that can be obtained by athletes when he/she train at specific altitude area of choice.

$a-$ Constant value.

$b_{i}$ - Coefficient of selected parameters in the OLS regression model;

$\varepsilon_{i}-$ Error factor in the model.

The use of parameter estimator in OLS regression model could reveal the level and magnitude of influence of altitude services which motivate athletes to choose specific zone and area of altitude for training. However, binary functions cannot be estimated through the ordinary least squares method, because the predicted values from the resultant linear probability model cannot be constrained to the required interval without imposing restrictions on the values of independent variables.

Most of the primary data collected in this study were dummies, which took the form "yes $=1$ " and " $\mathrm{No}=0$ ". Hence, to give meaningful statistics binary functions can be estimated through maximum likelihood methods. In this study logit model was selected for analysis of probability on the basis of easing computation.

In context to this study, the logit model postulates that the probability of athletes to make decision to train at specific altitude in order to obtain incremental running performance $(\mathrm{P})$ is a function of selected motivating altitude parameters $\left(X_{i} \ldots, X_{i}\right)$. These variables are presence of trainers, availability of trails, experiences, infrastructure, socio-economic factors, housing and others.

The model uses a logistic curve to transform binary responses into probabilities within 0 to 1 interval. The significance of computed Legit model value (P (i)) which is closer to 1 shows the variable to have higher influence while near zero or zero value reveal low influence or no significant influence. The parameter estimates in legit model can be specified as:

$$
P(i)=1 /\left(1+\exp \left(\beta_{i} X_{i}\right)\right)
$$

Where: $P(i)$ is the probability of athlete to make decision to train at specific altitude zone and area; $\beta_{i}$ is the coefficient value of specific variable and $X_{i}$ is the selected variable from 
the OLS regression model.

\section{Results and Discussion}

\subsection{Athletes Characteristic}

Descriptive statistics for the variables used in the empirical analysis are shown in Table 2. Based on pre test result, the variables identified described the relationship of athlete's characteristics and altitude services demands that motivates athletes to train in the study area.

Table 2. Descriptive Statistics of Athletes Training in the Study Area.

\begin{tabular}{lll}
\hline Variables & Mean value (n) & (\%) \\
\hline $\begin{array}{l}\text { Athletes Characteristics } \\
\text { Age }\end{array}$ & 27 years & - \\
Gender & & \\
Male & - & $56 \%$ \\
Female & - & $44 \%$ \\
Citizenship & & $76.7 \%$ \\
Local Athlete & - & $23.3 \%$ \\
Foreign Athlete & - & - \\
Cost Incurred by Athletes & & - \\
Local Athlete & $\$ 4.67$ per day \\
Foreign Athlete & $\$ 14.51$ per day \\
Athlete Speciality & & $4.5 \%$ \\
Short distance $(100 \mathrm{~m}$ to $400 \mathrm{~m})$ & - & $27.8 \%$ \\
Mid distance $(800 \mathrm{~m}$ to $5000 \mathrm{~m})$ & - & $67.7 \%$ \\
Long distance $(\leq 10000 \mathrm{~m})$ & - & \\
\hline
\end{tabular}

Source: Field data; $\mathrm{N}=223$; Exchange rate is Ksh $100=\$ 1$.
From the findings (Table 2), the average years of athletes in the study area was 27 years with majority being male at $56 \%$, while female were at $44 \%$. Findings revealed that majority of athletes train for long distance, mid distance and short distance at $67.7 \%, 27.8 \%$ and $4.5 \%$ respectively. Again, local athletes are seen to be the majority compared with foreign athletes. Study of [11] found athletes who train at an altitude above 2000 metres above sea level are often long distances since high altitude environment gives them incremental benefits for endurance.

Similarly, $[16,17]$ found athletes living at high altitude to benefit from acclimatization conditioning were they suggested adoption of acclimatization model 'live and train at high altitude'.

Acclimatization at high altitude is seen as an important body conditioning for mid and long distance runners. These high altitudes zones tend to motivates athletes to seek for altitude training with cost. Evidence is seen from the findings in Table 2 which shows that foreign athletes to bear high cost while seeking altitude training compared with local athletes. Thus, past studies $[11,16,17]$ reveals close relationship with the findings of this study.

\subsection{Economic Cost from Altitude Training Demands}

Table 3 show categories of athletes (local and foreign) who train at altitude to gain incremental performance and the type of costs incurred by athletes in terms of travel, accommodation and food.

Table 3. Estimates of economic cost to train at high altitude.

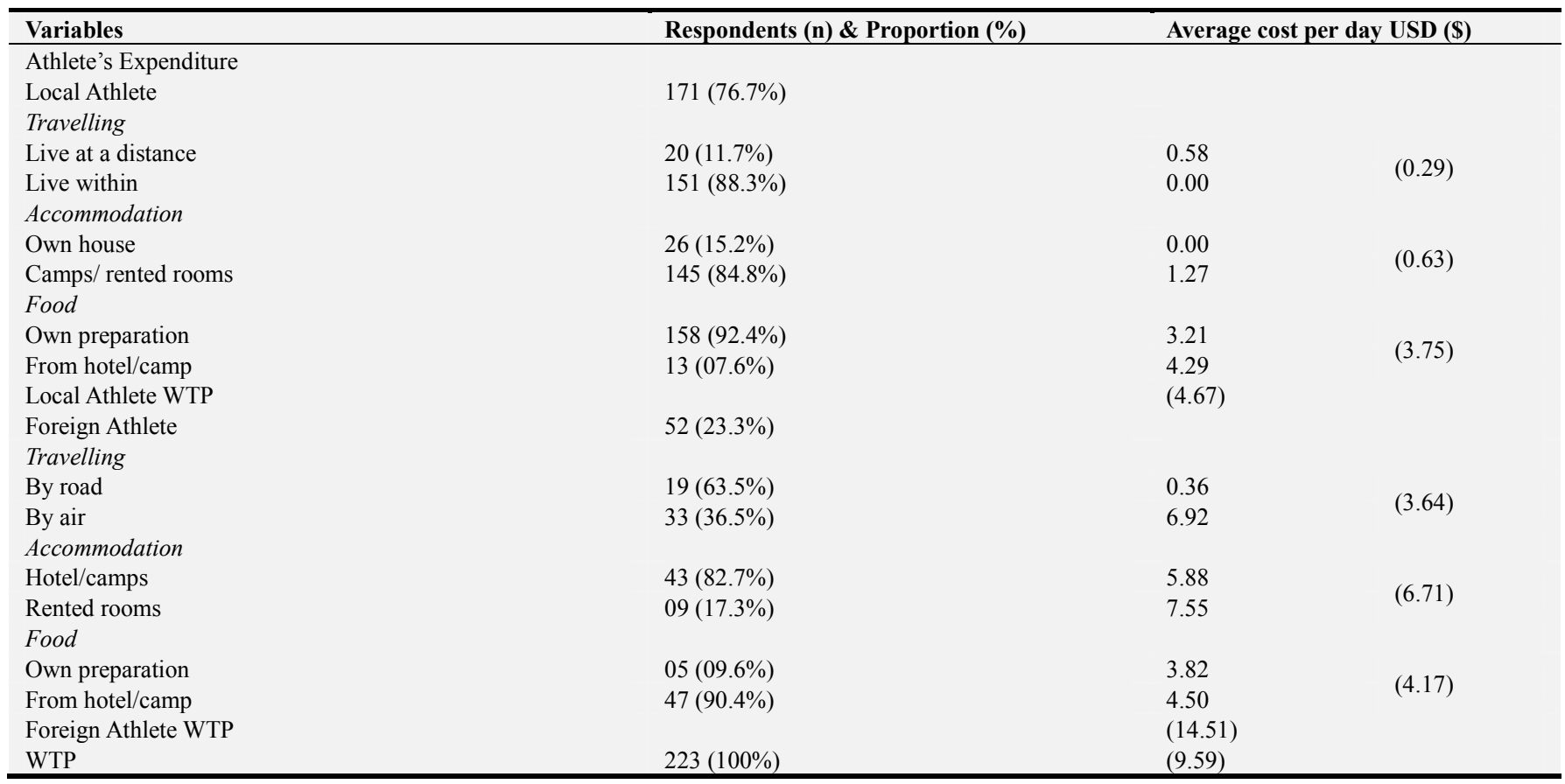

Source: Field data; $\mathrm{n}=223$; Most of foreign athletes reported to come for high altitude training for 3 months, based on that, mean value for travelling cost was calculated to determine cost per day; WTP $=\frac{\sum_{\mathrm{ij}}^{\mathrm{n}}{ }_{i j}}{\mathrm{n}}$ where $X$ represent athletes costs, $(i)$ represent category of athletes (local and foreign, $\mathrm{n}=2$ ), while $(j)$ represent types of costs (travel, accommodation and food, $n=3$ ); Exchange rate is Kshs $100=\$ 1$.

From the findings, proportion of local and foreign athletes interviewed were $76.7 \%$ and $23.3 \%$, respectively. Results 
showed that average cost incurred by local athletes per day while training at altitude is $\$ 4.67$, while foreign athletes incur \$ 14.51. Most local athletes (88.3\%) live within the study area; majority of them $(84.8 \%)$ rent rooms at the cost of $\$ 0.63$ to stay at altitude zone to gain incremental acclimatization benefits.

Since athletes stay at their own rented rooms, majority prepare their own food resulting to food costs cut compared with foreign athletes. The findings reveals further that hotels and training camps offers majority of foreign athlete's accommodation, though expensive which pushes athletes expenditure to higher levels compared with those living on rented rooms.

Altitude training demands can be measured using willingness of an athlete to incur cost in order to gain incremental benefits from altitude hypoxic exposure. Expressed willingness to pay by either local or foreign athlete to train in the study area was $\$ 9.59$, while expressed willingness to incur cost by local and foreign athlete separately was \$ 4.67 and \$ 14.51 per day.

Several studies [18, 19] used travel cost methods in determining economic value of environmental services. For instance, [19] valued various altitude zone namely summit, mid and low zones of Mt Everest where low-altitude zone was almost twice the average of trip cost. This study employed similar valuation approach of using expenditure incurred by athletes, which is willingness to pay value (WTP), as a measure of altitude services. Attributes of costs in this study are travelling and living expenses where living costs entails housing or rent and food cost.

\subsection{Motivating Factors for Athletes to Train in the Study Area}

When respondents were asked to identify key motivating factors that inform their preference and choice to train in the study area, majority pointed out experience from elite athletes, group training, ambient environment (altitude services) and coach advice. Figure 1 depicts proportion of variables that was highly ranked by the respondents.

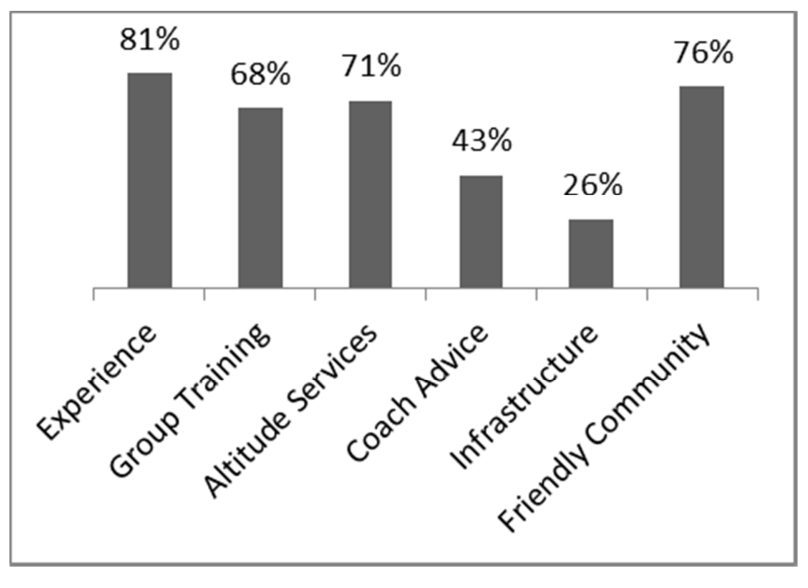

Source: Field data.

Figure 1. Covariates that motivates athletes to train in the study area.

Table 4. Results of legit model analysis depicting probability of influence by parameter estimators.

\begin{tabular}{|c|c|c|c|c|}
\hline Parameter $\left(x_{i}\right)$ & Equation function & SE & $\mathbf{P}(i)$ & $t$-test \\
\hline \multicolumn{5}{|l|}{ Athletes Characteristics } \\
\hline Age & $Y=-0.21 x+83.79$ & 1.02 & 0.55 & $0.019 *$ \\
\hline Gender & $Y=0.37 x+83.79$ & 0.21 & 0.36 & 0.895 \\
\hline Nationality & $Y=0.72 x+83.79$ & 0.97 & 0.32 & 1.034 \\
\hline \multicolumn{5}{|l|}{ Attributes of study area } \\
\hline Experience & $Y=-0.78 x+83.79$ & 0.34 & 0.69 & $0.094 *$ \\
\hline Group Training & $Y=0.52 x+83.79$ & 0.74 & 0.37 & 2.026 \\
\hline Coaching advice & $Y=0.28 x+83.79$ & 0.81 & 0.43 & 0.928 \\
\hline Sports infrastructure & $Y=1.91 x+83.79$ & 1.02 & 0.13 & 2.103 \\
\hline Safety at training area & $Y=0.03 x+83.79$ & 0.87 & 0.49 & $0.074 *$ \\
\hline Stochastic variables or Error term & $Y=0.35 x+83.79$ & 0.91 & 0.41 & $0.012 *$ \\
\hline
\end{tabular}

Source: field data NB: Equation function takes the form $Y=\beta x i+c$; where $\beta$ is coefficient value of specific parameter $x$, while $\mathrm{c}$ is the constant value (83.79) in the model i.e. when $\mathrm{xi}$ is zero then $\mathrm{Y}$ is 83.79 ; $\mathrm{P}$ (i) is the probability of influence by the parameter (it can be converted into percentages): SE - Error term in the model.

Most of athletes who chose to train in the study area ranked experience as a motivating factor. Apart from experience, other variables in order of ranking were friendly community, altitude services, group training, coach advice and infrastructure. Based on these results, it can be deducted that safety in the study area, environment training knowledge from coaches i.e. Acclimatization knowledge could influence athletes to make priori decision to train at high altitude areas and zones. For instance, athletes training in a group amidst elite runners could possibly impart experience to budding athletes. Although infrastructure in sports training is vital, surprisingly, it was ranked lowly. This could reveal sporting facilities are of low priority in absence of group training and safety.

\subsection{Probability of Influence by Parameter Estimators}

Logit model was used to determine probability of selected variables of athletes characteristic and attributes of high altitude to influencing willingness to incur cost (WTP) by athlete to gain altitude training benefits. Parameter estimators from the logit model in Table 4 revealed that gaining experience, age of athlete, safety and acclimatization at high altitude zones had higher probability to influence willingness to incur cost by training at altitude with $0.69,0.55,0.49$ and 
0.48 values respectively. Similar parameter estimators (experience, $\mathrm{t}=0.019, \mathrm{p}<0.05$ ), (age, $\mathrm{t}=0.094, \mathrm{p}<0.05$ ), safety, $\mathrm{t}=0.074, \mathrm{p}<0.05$ ) and (altitude, $\mathrm{t}=0.071, \mathrm{p}<0.05$ ) revealed to significantly influence willingness to incur cost for altitude training. Other parameters in the model (Gender, nationality, group training, coaching advice and sports infrastructure) showed low probability to influence willingness of athlete to train at high altitude compared with the later; however, its statistical tests were insignificantly difference.

Surprisingly, sports infrastructure which was expected to highly influence willingness to incur cost recorded the lowest probability to influence. This explained the fact that most athletes target endurance; thus, training using roads rather than track could serve the purpose.

Strikingly, age and experience in the OLS model parameter estimators showed negative values. This reveals the direction of relationship between parameters and willingness to incur cost by athlete when training at the study area; that's the older an athlete, the lesser the cost he/she incur. These could be supported by the fact that aged athletes have gained experience and probably stabilised financially and thus they own houses which allows them to cut living expenses.

Studies $[2,20,21]$ found income to be major determinants that influence consumer surplus, which explicate rationality of consumer in the utility theory. However, from the finding it revealed the contrary where inexperience and budding athletes expresses to incur higher cost than financially stable athletes. Further from the OLS parameter estimates model, it showed random factor value of $P(i)=0.41$. This random factor in the model revealed to have significantly influence. It also showed to marginally probability to influence athlete's decision making to incur cost while training in the study area. The stochastic variables in the legit model reveal that there exist parameter estimators which were beyond the scope of this study and were omitted by design or default which affected the model. Significant influence of error term from the model could suggest that further study on other unexplained parameters that are not in the model need to be investigated.

Table 5 present the results of bootstrap hypothesis testing described in equation 5, 8 and 9 in this study. These bootstrap hypothesis tests considers non-overlapping confidence intervals were the results of null hypothesis is rejected if the confidence interval of for WTP do not overlap. The condition for rejection is that actual significant level should be higher than significant level indicated by the tests [23]. The results in this study were consistent with bootstrap hypothesis testing condition.

Table 5. Bootstrap hypothesis testing results.

\begin{tabular}{lll}
\hline Null hypothesis & & Decision \\
\hline $\mathrm{H}_{0}: \mathrm{WTP}=0$ & 0.000 & Null hypothesis rejected \\
$\mathrm{H}_{0}: \mathrm{WTP}_{\mathrm{a}}=\mathrm{WTP}_{\mathrm{b}}$ & 0.018 & Null hypothesis rejected \\
$\mathrm{H}_{0}:\left(\mathrm{WTP}_{\mathrm{a}}-\mathrm{WTP}_{\mathrm{b}}\right) / \mathrm{b}<\left(\mathrm{WTP}_{\mathrm{a}}\right) / \mathrm{a}$ & 0.007 & Null hypothesis accepted \\
\hline
\end{tabular}

Source: Field data.
It can be deduced from hypothesis testing results that athletes are willing to incur cost to gain incremental altitude training. Preferences to train at high altitude for incremental running performance obtained from this study are "wellbehaved" and are consistent with economic theory.

\section{Conclusion}

Travel cost method is suitable for valuing non-market environmental service that is in demand with premise that the total cost incurred in visiting an area supplying demanded service can be used to measure economic value of that environmental services. High altitude provides environmental services provision to athletes through acclimatization effect and thus demand function.

The hypoxic condition of various altitude zones have long been known in sports training to have psychological and physiological effects. Seeking such incremental demands of hypoxic conditions at preferred altitude area or zone relative to non-hypoxic condition area tend to impact on individual's economy. Economic cost incurred while seeking such high altitude services are often used in measuring economic value of non-market environmental services.

Travel cost has various variations to individual which needs modification while analysing travel cost valuation techniques. They are suitable under different circumstance because it could result into different valuation outcome. It is therefore important to employ travel cost model which gives the most optimal economic cost i.e. inclusive of living expenses, while seeking environmental service as depicted by the findings in this study.

Since living expenses (accommodation and food) in this study are critical in determining economic value of high altitude services, it is therefore recommended in view of its significance then it should be incorporated while analysing economic value of a resources in demand function i.e. Travel cost and Hedonic valuation models. However, the selected variables in this study seem to be limited and cannot solely be relied upon as depicted by marginal significance of the stochastic variable in the regression model. It is therefore recommended that other variables which were beyond the scope of this study be investigated.

\section{Acknowledgements}

The authors thank various coaches and athletes both local and foreign who participated in giving out their valuable information concerning their training at Iten Township.

\section{References}

[1] Pagiola, S. (2009). Payment for Environmental Services: An Introduction. Presentation at Environment Department. World Bank. Washington. http://www.siteresources.worldbank.org/INTEEI/Resources/In troToPES.pdf. 
[2] Barbier E., S. Hacker, C. Kennedy (2011). The value of estuarine and coastal ecosystem services. Ecol Monogram 81 (2): $169-193$. https://esajournals.onlinelibrary.wiley.com/doi/pdf/10.1890/10 -1510.1 .

[3] Pant K. P., Rasul, G., Chetri, N., Rai, K. R. and Sharma, E. (2012). Value of forest ecosystem: a quantitative estimation from the Kangchenjunga Landscape in Eastern Nepal. Kathmandu. ICIMOD working paper 2012/5.http://www.fao.org/library/library-home/en/.

[4] Kerr, M. J., Vardhan, M., \& Jindal, R. (2014). Incentives, Conditionality and Collective Action in Payment for Environmental Services. International Journal of the Commons, 595-616. DOI: http://doi.org/10.18352/ijc.438.

[5] Rideout A., N. Joshi and K. Viergever (2013). Making predictions of mangrove deforestation: a comparison of two methods in Kenya. Glob Chang Biol 19: 3493-501 SCBD (2009) Biodiversity for development and poverty alleviation. Secretariat of the Convention on Biological Diversity, Montreal. https://doi.org/10.1111/gcb.12176.

[6] Derby, R., and K. de Weber (2010). The athletes and High Altitude. Current Sports Medicine Report (American College of Sports Medicine), 9 (2): 79-85.

[7] Hacket P. H. and R. C. Roach (2012). High-altitude medicine and physiology. In: Auerbach PS, ed. Wilderness Medicine 6th ed. Philadelphia, PA: Mosby.

[8] Vargas-Pinilla and Olga-Cecilia (2014). Exercises and Training at Altitude: Physiological Effects and Protocols. S. Rev. Cienc. Salud. Vol 12 (1): 107-122. Doi: dx.doi.org/10.12804/revesalud12.1.2014.0710.1111/j.16000838.2008.00835.x.

[9] Barjarmovic, E.; Habul, C.; Talovic, M.; Mekic, A.; Narcotic N. and S. Likic (2018). Effects of 8-Week Muscular Endurance Training with Body Weight in the Case of Recreational Athletes. Homosporticus 20 (1): 47-51.

[10] Zhang G, Zhou S. M, Yuan C, Tian H. J, Li P, and Y. Q Gao (2013). The effects of short-term and long-term exposure to high altitude hypoxic environment on neurobehavioral function. Journal of High Altitude Medical Biology. 14: 338341 .

[11] Khodaee, M., Grothe Heather L., Seyfert Jonathan H. and Karin Van Baak (2016). Primary Care: Athletes at High Altitude Journal of Sports Health Vol 8 (2): 126-132. DOI: 10.1177/1941738116630948.

[12] Murali, Ranjini; Redpath, Steve and Mishra, Charudutt (2017). The value of Ecosytem Services in the High Altitude
Spiti Valley, Indian Trans-Himalaya Ecosystem Services 28: 115-123.

[13] Howley, P., C. Buckley, O. Donoghue and M. Ryan (2015) Explaining the economic "irrationality" of farmers land use behaviour. The role of productivity, attitudes and non pecuniary benefits. Ecological Economics Journal 2015: 186193.

[14] Kenya Meteorological Department, 2013. The outlook for the March-April-May (MAM) 2013 "long-Rains" season in Kenya and Review of the performance of the OctoberDecember 2012 "Short Rains" Seasons as well as the weather during January-February 2013. Report from Government of Kenya [online], [cited 14 February 2018]. Available at: https://reliefweb.int/sites/reliefweb.int/files/resources/The $\% 20$ outlook\%20for\%20the \%20March-AprilMay\%20\%28MAM\%29\%202013\%20\%E2\%80\%9CLongRains\%E2\%80\%9D\%20season\%20in\%20Kenya.pdf.

[15] Kothari. (2004). Research Methodology: Methods \& Technology (2nd ed.). New Dheli, India: New Age International Publishers.

[16] Campbell A. D., McIntosh S. E., Nyberg A., Powell A. P., Schoene R. B. and P. Hackett (2015). Risk stratification for athletes and adventurers in high altitude environment: recommendation for pre-participation evaluation. Clinical Journal Sports Medicine 25: 404-411.

[17] Bloch K. E., Buenzli J. C., Latshang T. D and S. Ultrich (2015). Sleep at high altitude: guesses and facts. Journal of Applied Physiology (1985). 119: 1466-1480.

[18] Layton Robert and Wallace G. (2006). Is Culture a Commodity? pp: 275-285. Doi: 10.1017/cb09780511817656.004.

[19] Choi, Andy; Ritchie, Brent; Papandrea, Franco and Bennet, Jeff (2010) Economic Valuation of Cultural Heritage Sites: A Choice Modelling Approach. Tourism Management Vol 31 (2): 213-220. Doi: 10.1016/j.tourism.2009.02.014.

[20] Ting, Chung-Te; Hsieh, Chi-Ming, Chang, Hsiao-Ping and Chen Han-Shen (2019). Environmental Consciousness and Green Customer Behaviour: the moderating Roles of Incentives Mechanisms. Sustainability 11 (819): 2-16 Doi: $10.3390 /$ su11030819.

[21] Bias, P. V.; Smith, Patrick L. and Jansson, Hanna (2012) In Defense of Rationality Assumption; Conference Paper, July 2012. pp: 1-16.

[22] Avery, Kelly and Freeman, Laura (2017). Statistical Techniques for Modelling and Simulation Validation. Simulation Innovation Workshop 2017. IDA. 